\title{
Empirical Study on the Influencing Factors of WeChat Business Integrity
}

\author{
Yangling Xiao, Northeast Petroleum University, Heilongjiang, China \\ Bingjun Tong, Northeast Petroleum University, Heilongjiang, China \\ Mingxin Cui, Northeast Petroleum University, Heilongjiang, China \\ Yanmei Sheng, Northeast Petroleum University, Heilongjiang, China \\ Xiaobeng Wei, School of Economics and Management, Northewast Petroleum University, Daqing, China \\ Jie Luo, School of Economics and Management, Northeast Petroleum University, Daqing, China
}

\begin{abstract}
With the increasing popularity of smartphones and electronic payment, WeChat shopping has become a trendy lifestyle for many people. However, the issue of WeChat business integrity has gradually appeared due to the virtuality of the internet. This paper analyzes the current situation of the development and integrity of WeChat business, and the differences and connections between WeChat business and traditional e-commerce. Based on theoretical and practical analyses, this paper puts forward the influencing factors of WeChat business integrity and related hypotheses. Data collected through questionnaires are evaluated by reliability and validity with SPSS24.0; after that, empirical analysis is conducted to the structural equation model. The results indicated that products and service quality, after-sale guarantee, payment security, and word-of-mouth had a prominent positive effect on the integrity of WeChat business, of which product and service quality have the greatest impact; this is followed by payment safety, after-sales service, and word-of-mouth, which has the smallest impact on WeChat business integrity. At the same time, it offers countermeasures to improve the quality of products and services, ensure payment safety, improve the after-sales guarantee and establish a good reputation, so as to enhance the credibility of WeChat business and achieve sustainable development.
\end{abstract}

\section{KEYWORDS}

Empirical Analysis, Influencing Factors, Integrity, WeChat business

\section{INTRODUCTION}

In recent years, e-commerce has flourished, especially with the emergence of social networks such as Facebook, Twitter, WeChat, and Weibo, and they have affected the way people work, socialize, access information, and shop online. In China, the WeChat app function, "WeChat Friendship Circle," provides people with an increasing amount of opportunities to start up new businesses ( $\mathrm{Li}, 2017$; Chu, 2018). A WeChat-based businesses is based on a new business model in the WeChat mobile app that uses the help of social software and social networking. There has been a rapid development of big data in terms of data mining (Chang \& Yang, 2017), complex event analysis and multimedia event recognition (Chang, Ma, Yang, Zeng, \& Hauptmann, 2017; Chang, Yu, Yang, \& Xing, 2017; Li, Nie \& Chang, 2017), multimedia social networks that are based on trust (Li, Zhang, and Zhang,

DOI: 10.4018/JGIM.20220701.oa4

This article published as an Open Access article distributed under the terms of the Creative Commons Attribution License (http://creativecommons.org/licenses/by/4.0/) which permits unrestricted use, distribution, and production in any medium, provided the author of the original work and original publication source are properly credited. 
2018), cloud-based manufacturing composite services (Namjoo, Keramati, \& Torabi, 2018), rapid sensor detection (Chang, Ma, Lin, Yang, \& Hauptmann, 2017), information technology for smart cities (Maestre-Gongora \& Bernal, 2019), information and communications technology (Morrar, Abdeljawad, Kisa, \& Younis, 2019), regulatory effect of consumer cognition innovation based on the S-O-R model (Osmal, Kang, \& Iwona1, 2019) and database security (Sangeeta \& Narsimha, 2018) to provide a technical basis for the development and maturation of the WeChat-based businesses model. According to the Statistical Report on the Development of China's Internet Network released by the CNNIC, the usage rate for WeChat has been increasing year by year since the appearance of its "WeChat Friendship Circle." By December 2017, the usage rate for WeChat reached 87.3\% (Shan, 2018). WeChat has become a new way of doing business in China, and it can be seen as a combination of traditional e-commerce and social network communication. A WeChat-based business develops its customer relationships in two ways, through business relationships and friendships (Yang, 2016). One WeChat-based business entered the consumers' range of vision with a new marketing model (i.e., opening a shop based in the WeChat Friendship Circle) in 2013 by disseminating across social platforms pictures of various products, including cosmetics, healthcare products, and clothes.

With the rapid development of WeChat-based businesses, the issue of integrity has come to the forefront. The false propaganda about some virtual trade events has seriously damaged the interests of consumers. For example, the "toxic facial mask" incident involved changing the appearance of young girls into the "Green Lantern." On September 30, 2016, CCTV exposed the "consumption trap of WeChat about pyramid selling," which made consumers doubt the reliability of WeChat products as well as the integrity of WeChat-based businesses. The undated products and the false propaganda led to a discussion about WeChat-based businesses by scholars. The research about this topic mainly involves three aspects:

1. Studies concerning the current status of WeChat-based businesses. The studies on WeChat-based businesses, especially with college students, showed that many college students avoided WeChatbased purchases due to their low product quality, unreasonable prices, and there being a lack of a guarantee policy (Shi, 2017; Wang, 2017). When WeChat-based businesses first developed, one of their advantages was that they required less of a threshold and had simpler procedures compared to other forms of e-commerce (Zhang, 2018); Because of the characteristics mentioned above, a chaotic situation formed since anyone can engage in the WeChat-based business industry without training and verification, which had a negative effect on the management and development of WeChat-based businesses (Wang, 2019).

2. The development trends for WeChat-based businesses. It had been predicted that WeChat-based businesses would become a common business form in the future since they would draw more people into business (Hu, 2016; Liao, 2016). The development trend for WeChat-based businesses can be summarized as follows: Industry standardization, WeChat platform and community, and WeChat-based businesses (Lan, 2018). Most of the WeChat-based businesses exist in the form of WeChat-based business agents who don't have any products, and it is expected that these WeChat-based business agents will be eliminated (Zhang, 2018).

3. The integrity of WeChat-based business operations. Some individual operators post fake transfer records, chat records, etc., using certain tools in WeChat's circle of friends. Once the false information is exposed, consumer trust in the entire micro-business platform is greatly reduced. (Fu, 2018). Integrity problems in the WeChat-based business operations include false advertising and difficulties had protecting consumer rights (Wang, 2014), product quality issues and aftersales protection issues (Qian, 2016), the imperfections of the regulatory system and a lack of standardization in the market (Wang, 2017), the insecurity of the payment methods (Li, 2017), and the virtual nature of the transactions (Fu, 2019). 
According to the literature review, the current research on WeChat-based business integrity focuses on the issues of integrity and their countermeasures, and there is no systematic research on the factors influencing WeChat-based business integrity. Therefore, empirical research on the factors influencing WeChat-based business integrity is particularly necessary. On the basis of the related research in this field, this paper focuses on WeChat-based businesses in terms of consumer feelings toward the WeChat shopping circle while incorporating the structural equation model to explore the important factors affecting WeChat-based business integrity. The significance of the research is mainly reflected in the following aspects. First, the research on the factors influencing WeChat-based business integrity provides a new perspective for research on WeChat-based business behavior. Second, the application of the structural equation model has been expanded to provide theoretical support for WeChat-based business integrity management. Third, by identifying the main factors influencing WeChat-based business integrity, WeChat-based businesses can take effective steps toward building a better image, gaining the trust of their consumers, and achieving a continuity of transactions.

\section{WECHAT BUSINESSES AND TRADITIONAL E-COMMERCE}

\section{The Development of WeChat-Based Businesses}

WeChat-based businesses are a new type of electric business with a low entry threshold and needing less of an up-front investment, and they attract a large number of social groups, such as lower-paid workers, college students, and full-time housewives. According to a data analysis from the report on micro-business development from the Chinese Internet Association (China Internet Society Weishang Working Group, 2016-2017), the number of employees in this industry increased yearly from 2014 to 2017, and the growth rate of the number of employees in 2016-2017 was significantly higher. The reason for this was the wider availability of the $4 \mathrm{G}$ network, which promoted people's understanding of online products in first-, second- and third-tier cities and rural areas. An increasing number of people joined WeChat, and the number of self-employed users of WeChat-based businesses reached 20 million in 2017. WeChat-based businesses also helped to increase the income of low-income groups. The number of employees for WeChat-based businesses from 2014 to 2017 is shown in Figure 1.

Source: Development Report on China's WeChat-based Business Industry in 2017.

The WeChat-based business market size expanded from 2014 to 2017. Its market size during these years is shown in Figure 2. The market size for WeChat-based businesses reached 700 billion yuan in 2017. Though the growth rate of the market size declined in 2017, it still increased by 322.85 billion yuan when compared to 2016. It was estimated that the overall spread of WeChat-based businesses would reach a higher levels in the future.

Source: Development Report on China's WeChat-based Business Industry in 2017.

WeChat-based businesses play an increasingly important role in the market economy, as the number of employees and market size involved rises year to year. Based on different platforms including Weibo, Forumsm and Renren, WeChat-based businesses transformed from being personal purchasing agents focused on fan management in 2011 to branding and normalization in terms of another business model in 2017. However, according to a survey conducted by the China Consumer Association, the dissatisfaction rate of WeChat-based businesses is $5.6 \%$, which was the highest among other standard online business models, as shown in Figure 3. The reason for this is that the quality and the price of products were uneven, and it was difficult to distinguish good products from the bad ones since there were too many options for commodities, which led consumers to have a negative impression of WeChat-based businesses.

Source: Statistical Report on Internet Development in China in 2017. 
Figure 1. Number of Employees in WeChat-based businesses 2014-2017

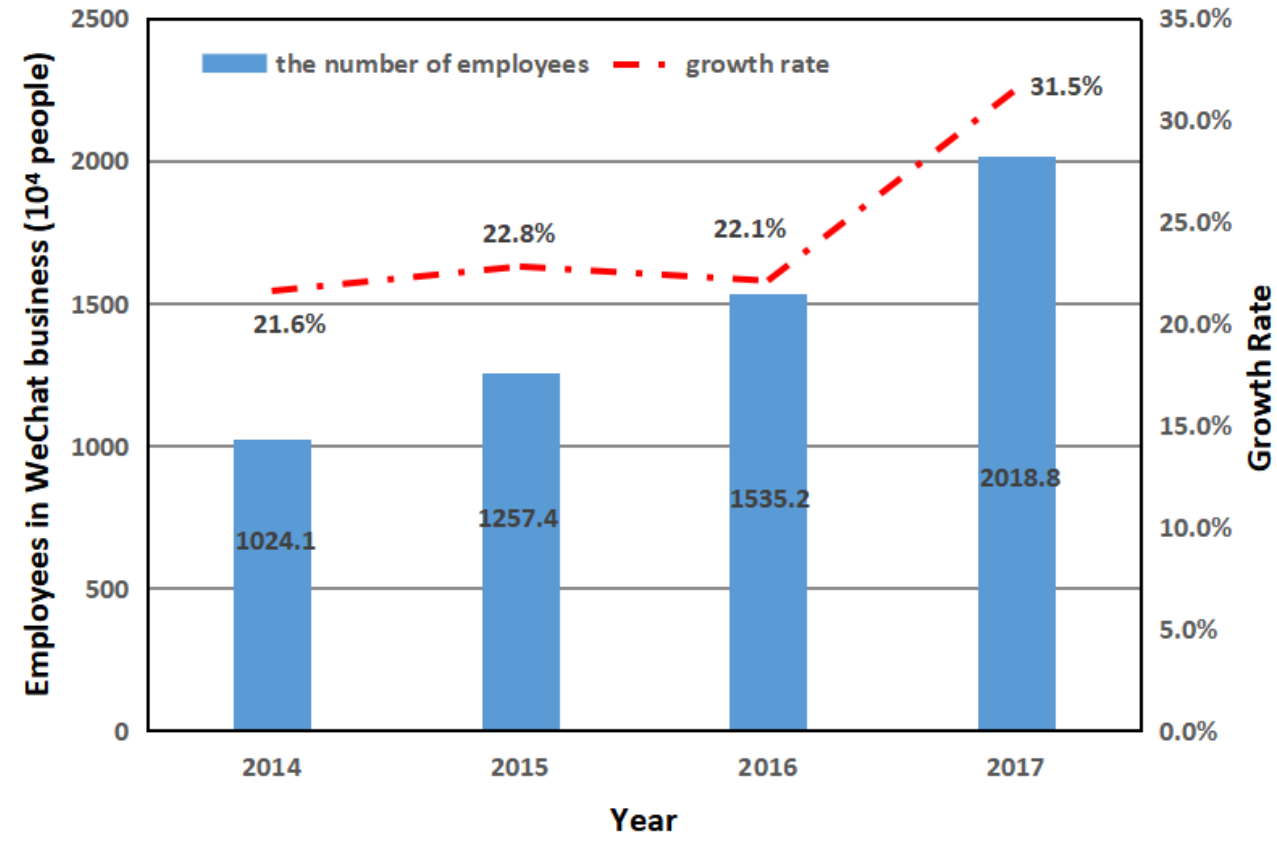

Figure 2. Overall scale of WeChat-based businesses 2014-2017

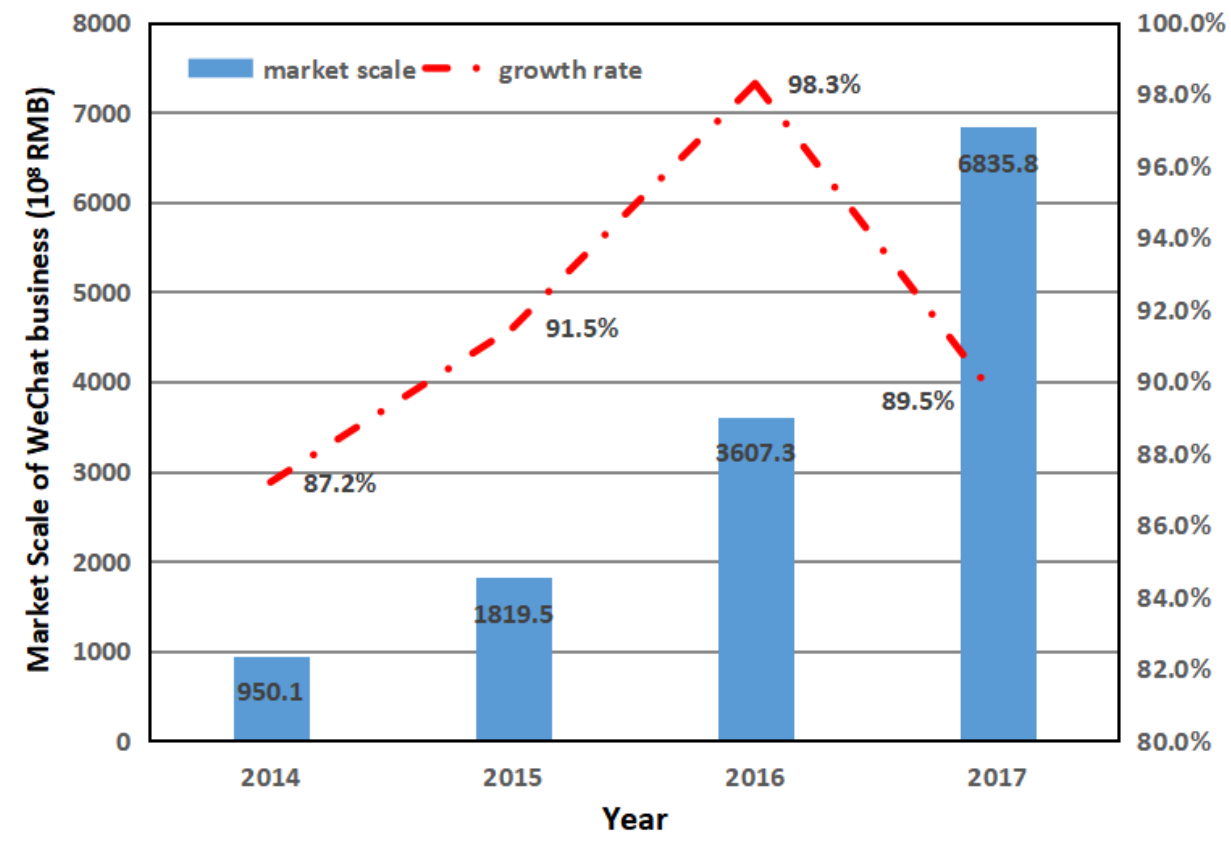




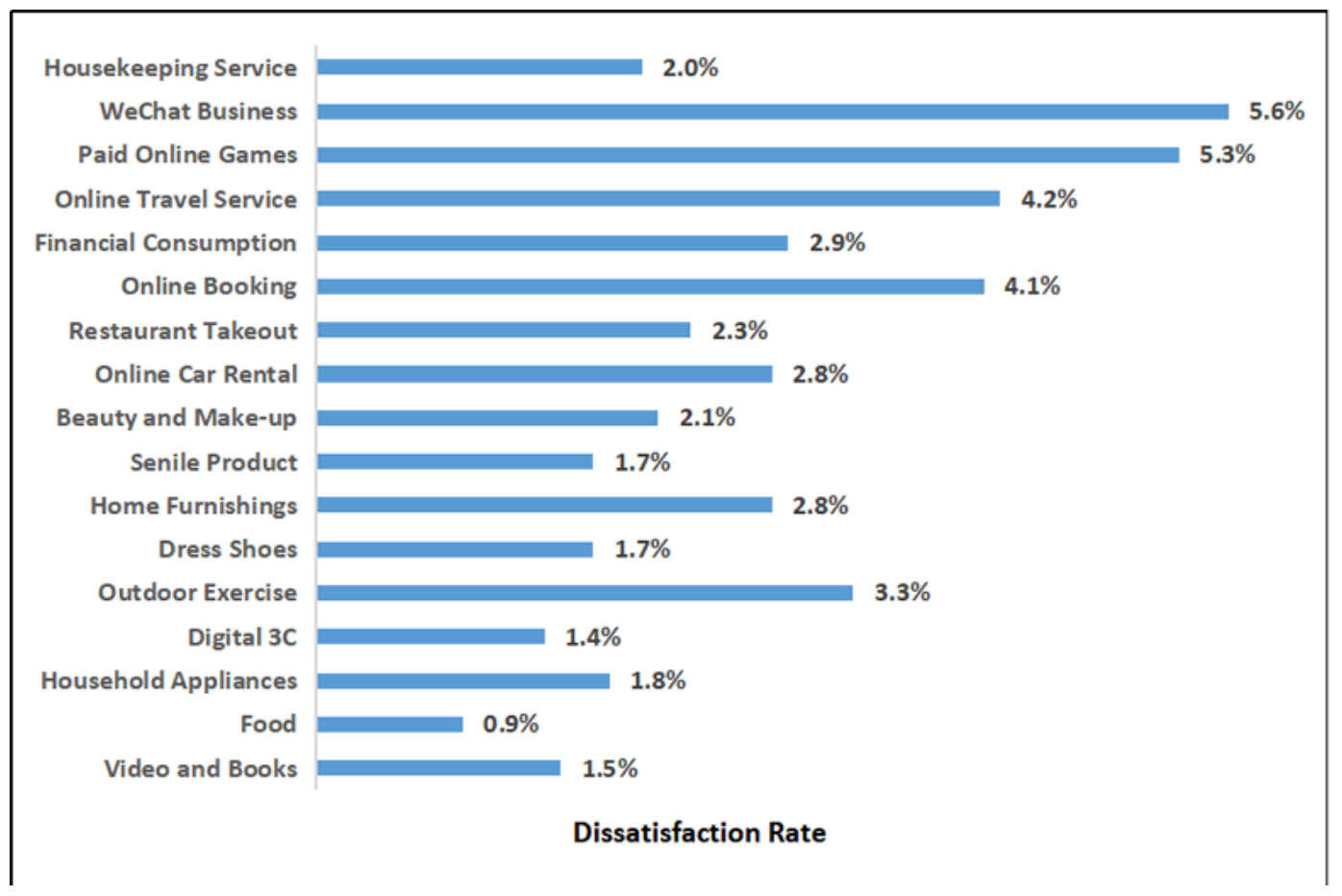

\section{Similarities and Differences between Traditional E-Commerce and WeChat-Based Businesses}

WeChat-based businesses provide a new business model found on WeChat's public account or in the WeChat friends circle. Compared with traditional e-commerce, the main differences between WeChatbased businesses and traditional e-commerce are as follows: (1) The purchasing model for traditional e-commerce (Taobao, Jingdong, Amazon, eBay, etc.) is usually online shopping on certain websites with certain products. However, WeChat-based business owners tend to focus on the application of the social app and introduce popular or desired products via communication and app sharing. (2) Traditional e-commerce businesses mostly deal with strangers on Internet platforms. WeChat-based businesses tend to promote and introduce customers among their acquaintances. For individual sellers, the cost of maintaining a WeChat-based business is much lower than that of traditional e-commerce.

Taking Taobao as an example, there are great differences between WeChat-based businesses and those on Taobao. First, there are different ways to obtain a greater sales volume. Taobao's way of obtaining a greater sales volume is mainly generated through Taobao's customer flow and paid promotion, while WeChat-based businesses' way of obtaining a greater sales volume is through the WeChat group and interpersonal circle, and the sales volume is mainly determined by the number and quality of friends. Second, WeChat-based businesses pay more attention to trust. While shopping on Taobao, consumers are accustomed to determining whether or not the sellers are honest in terms of their sales volume, commodity evaluation, and credit rating in the Taobao store. The payment funds involved in Taobao trading are saved on the Taobao platform, which is conducive to consumer protection for their legitimate rights and interests. Meanwhile, the trading method for WeChat-based businesses is that consumers directly pay WeChat-based enterprises, so winning consumer trust is one of the keys to a business's success. Third, the scope of the businesses is different. Each shop on Taobao can only sell one kind of product. If there are too many product categories, the sales volume 
typically decreases. However, the product categories for WeChat-based businesses can vary. As long as consumers trust WeChat-based businesses, they can sell any trustworthy products to their consumers. Fourth, different amounts of funds are invested. Taobao requires at least 1000 yuan for a security deposit to open a shop, while WeChat-based businesses can conduct transactions as long as they have a mobile phone. They also do not need to pay any security deposit. In addition, the products provided by WeChat-based businesses are generally produced by that particular business or obtained directly from factories or primary agents, and they can be delivered directly to consumers. As such, there is no pressure to maintain a certain amount of inventory or to pay rent to do so.

In the mobile network, the similarities between WeChat-based businesses and traditional e-commerce companies include (1) They both rely on the mobile network to be the carrier to achieve all of their commercial work, which is referred to as mobile e-commerce, and (2) their business activities are the same. They both include e-commerce activities that enable the trading of goods (to achieve pre-transaction information communication, online order transmission, and payment in transactions, and after-sales services of transactions via the Internet) and various business activities that facilitate these transactions, such as online commodity displays and online public relations.

\section{THEORETICAL ANALYSIS AND RESEARCH HYPOTHESIS}

In China, the theory of "integrity" originates from Laozi. In the literal sense, "integrity" is a comprehensive reflection of "honesty" and "creditability." "Honesty" is essentially a reflection of moral quality. It emphasizes the attitude and way of doing things by different people. "Creditability" is the kind of trust obtained by the mutual compliance performed in commercial activities.

The popularity of social media and the information shared on social media platforms greatly helps consumers make better shopping decisions regarding products, brands, and services (Christina, 2019). In terms of the micro-business transactions, the problem related to the integrity of WeChatbased businesses can be summarized as follows:

1. Quality and service issues. WeChat shopping can't be compared with traditional shopping methods like shopping malls where the actual products can be observed and examined. Some WeChat-based businesspeople exaggerate the quality of their goods and use overly decorative pictures (Wang, 2014).

2. After-sales problems. WeChat shoppers often complain that the quality of the after-sales service of WeChat-based businesses is low. Some WeChat-based business owners who display a great amount of enthusiasm before a purchase later turn their backs on consumers and ignore their complaints once their payment has been secured (Qian, 2016).

3. Payment security issues. WeChat-based businesses do not have a specific third-party payment platform. For users, there are security issues related to direct payment transfers, and this is not conducive to the standardized management of WeChat-based businesses (Li, 2017).

4. Word-of-mouth. In order to increase their trading volume, some WeChat-based businesspeople falsify screen shots that display customer praise. This altered feedback produces the illusion of a good reputation for WeChat-based business products, thus enticing consumers to purchase their goods.

To sum up, this paper theoretically analyzes the factors influencing WeChat-based business integrity in terms of four aspects: Products and service quality, after-sale guarantees, payment security, and word-of-mouth. 


\section{Products and Service Quality}

Products and service quality is a major concern of WeChat-based businesspeople and consumers. It affects the integrity of the dealers directly. According to the Report on Online Shopping Integrity and Consumer Cognition (2017), 70\% of consumers pay more attention to the quality of products and service when they are online shopping. The product information for WeChat-based businesses is mostly sent by either the seller or from the production company, in which case the authenticity has to be tested. In addition, most of the products have not been inspected by the industry or commercial administrative departments (Zhang, 2018). Product quality has a great impact on the WeChat-based business integrity $(\mathrm{Li}, 2017)$. Products with higher quality and a better service attract more consumers. On the other hand, products that have a lower quality and a lower amount service will arouse consumer suspicion about the integrity of the WeChat-based business and thus reduce the rate purchases. Based on these facts, the following research hypothesis is drawn:

Hypothesis One: Products and service quality have a significant positive impact on the views WeChat-based business integrity.

\section{After-Sale Guarantees}

One of the biggest problems for WeChat-based businesses is that it is difficult for consumers to protect their rights, and there is almost no guarantee for after-sales service. Unlike Taobao, which has a specialized third-party platform, WeChat-based businesses rely on direct consumptions within the WeChat friendship circle, which leads to there being almost no supervision for transactions. The main factors affecting consumer purchasing decisions include the commodities' characteristics, WeChatbased business service capabilities, and the after-sales guarantees offered (Li, 2015). Compared with the after-sales service model of traditional physical stores, WeChat-based businesses' after-sales service are inconvenient, especially regarding product returns. It is difficult for consumers to solve any of their problems with a product when there are complicated procedures and a long waiting time (Shen, 2019). Since most of the products sold by WeChat-based businesses are not among the hottest-selling brands on the market and since most of them are imported products from overseas that cannot be purchased on the local market, there are often no after-sale guarantees. Thus, most WeChat-based businesses have a "no-return" policy (Fang, 2019). Based on this, the following research hypothesis is drawn:

Hypothesis Two: After-sales guarantees have a significant and positive impact on the view of WeChat-based business integrity.

\section{Payment Security}

Payment security is the most important issue in the transaction process, and it has a significant impact on building buyers' trust (Jiao, 2015). Whether it is a B2C or C2C business model, the entire transaction process only involves consumers and WeChat-based businesses. Usually, the first step for WeChat-based businesses is that the consumer makes a payment to the micro-business through WeChat or Alipay, and then the seller arranges delivery after the payment has been confirmed. Some merchants take advantage of the principle of "pay before delivery" to commit fraud in their circle of friends. Due to a lack of supervision from a third-party platform like Alipay, there are risks for both the seller and the buyer since the payment is conducted through the WeChat app (Hui, 2019). Based on this, the following research hypothesis is drawn:

Hypothesis Three: Payment security has a significant and positive impact on the view of WeChatbased business integrity. 


\section{Word-of-Mouth}

The concept of "word-of-mouth" originated in the field of communication, and it is the oral communication of a person's certain conduct (Amdt, 1967). In addition, word-of-mouth is also defined as the information exchange of a series of consumer opinions and evaluations toward a certain product or brand (Magnus, 1998). Consumers are affected by good or bad feedback when searching for shopping information on WeChat-based businesses (Christina, 2019). Trust and past shopping experiences have a significant impact on customer views of seller integrity (Jiao, 2015). In this paper, word-of-mouth is referred to as a two-way interaction in which the consumer transmits information about a certain product or brand to another customer through a certain type of communication, without any third-party processing, and which affects their purchasing behavior. At present, most consumers determine whether or not WeChat-based businesses are operating with integrity by means of wordof-mouth since consumers tend to buy goods from familiar friends. Based on this, the following

Figure 4. The Model of the Factors that Influence views of WeChat-based business Integrity

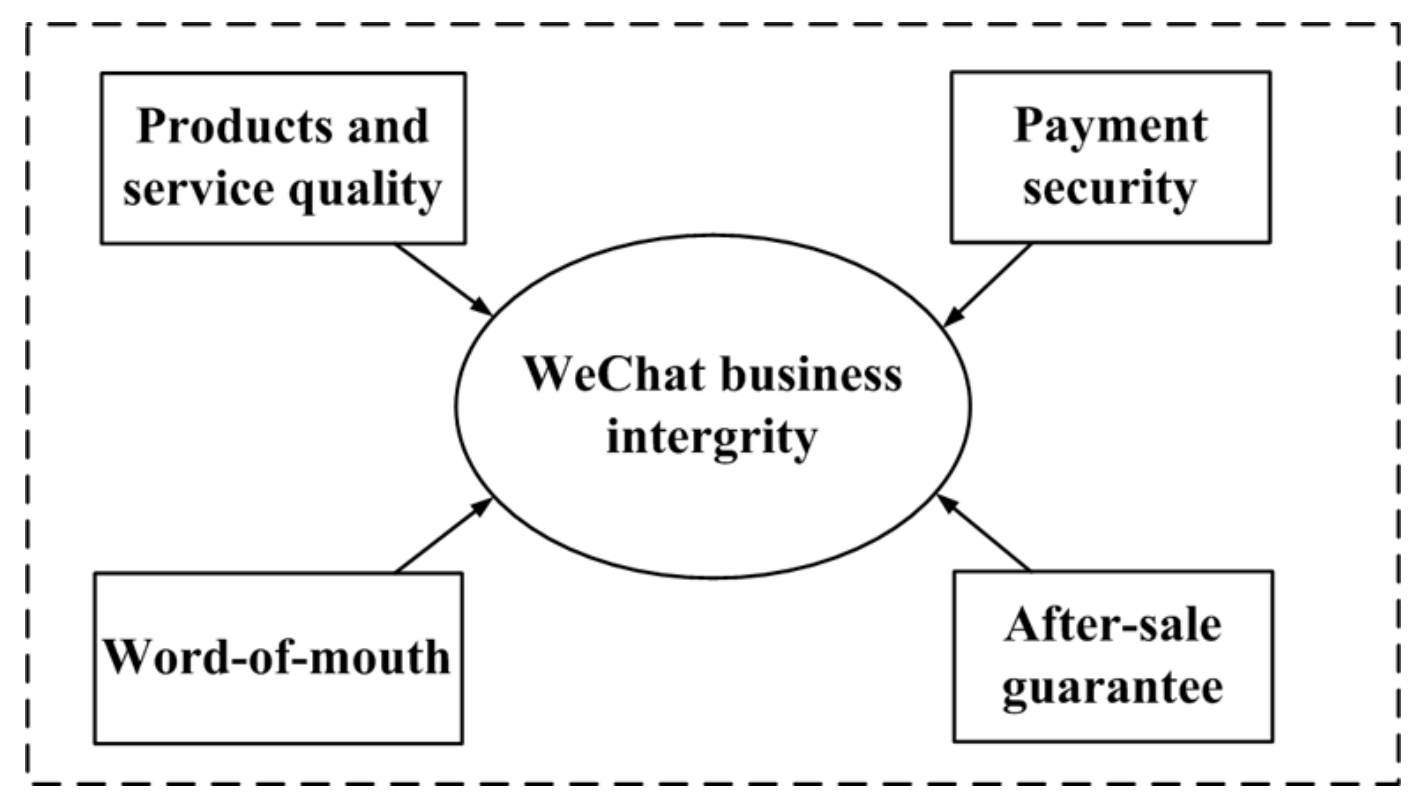

research hypothesis is drawn:

Hypothesis Four: Word-of-mouth has a significant and positive impact on the view of WeChat-based business integrity.

The summarized model of the factors influencing the view of WeChat-based business integrity is shown in Figure 4, framed by the above hypotheses. 
Table 1. Variable Measurement of Influencing Factors of WeChat-based businesses Integrity

\begin{tabular}{|l|l|}
\hline \multicolumn{1}{|c|}{ Variable Name } & \multicolumn{1}{c|}{ Measuring Item } \\
\hline $\begin{array}{l}\text { Products and service } \\
\text { quality }\end{array}$ & $\begin{array}{l}\text { The merchandise of WeChat-based businesspeople includes certified products. } \\
\text { The prices of the merchandise are marked clearly and match with the quality of the } \\
\text { merchandise. } \\
\text { WeChat-based businesspeople provide good service and on-time delivery. }\end{array}$ \\
\hline After-sale guarantees & $\begin{array}{l}\text { WeChat-based businesspeople will make a refund voluntarily if the merchandise has any } \\
\text { quality problems. } \\
\text { You are satisfied with the attitude of the WeChat-based businesspeople when dealing with } \\
\text { complaints. } \\
\text { WeChat-based businesspeople pay a return visit on their own initiative after the purchase. }\end{array}$ \\
\hline Payment security & $\begin{array}{l}\text { WeChat can be used directly to pay for goods. } \\
\text { Personal information will not be disclosed when the payment is made. } \\
\text { The security of the funds is ensured in the transaction when the payment is made. }\end{array}$ \\
\hline Word-of-mouth & $\begin{array}{l}\text { Consumers tend to take recommendations from an authoritative third-party when WeChat } \\
\text { shopping. } \\
\text { Consumers prefer to shop with highly praised WeChat-based businesses. } \\
\text { Consumers are willing to shop with the WeChat-based businesses recommended by their } \\
\text { friends. }\end{array}$ \\
\hline $\begin{array}{l}\text { WeChat-based business } \\
\text { integrity }\end{array}$ & $\begin{array}{l}\text { The quality of the products that the WeChat-based businesspeople describe matches the } \\
\text { purchased products. } \\
\text { If a purchaser's consumption interests are violated, WeChat-based businesspeople take } \\
\text { responsibility voluntarily. } \\
\text { For shoppers on WeChat, WeChat-based businesspeople offer a guarantee and refund policy. }\end{array}$ \\
\hline
\end{tabular}

\section{QUESTIONNAIRE DESIGN AND DATA ANALYSIS}

\section{Questionnaire Design}

The questionnaire used for this study was designed to have two parts. One part includes statistics for the basic information of the survey object, and the other is the investigation of WeChat-based business integrity as well as the factors that impact it. There are 15 multiple-choice questions on the questionnaire. Among them, 12 questions are about the factors that influence one's view of WeChat-based business integrity, and the others are about WeChat-based businesses integrity. The measurement for this scale is the Lee Kotter's 7-point system: $1=$ very inconsistent, $2=$ inconsistent, $3=$ relatively inconsistent, $4=$ average, $5=$ relatively consistent, $6=$ consistent, and $7=$ completely consistent. See Table 1 for details.

\section{Data Survey Description}

This paper uses a questionnaire method to collect the data for the factors that influence how people view WeChat business integrity. The collection of the data occurs through on-site anonymous surveys and online anonymous surveys (Questionnaire Star). The questionnaire was completed from July 2018 to September 2018. Through the analysis of 312 questionnaires that were obtained, there are 292 valid questionnaires, accounting for $93.6 \%$ of the total. The statistical information obtained from the questionnaire is shown in Table 2.

In the process of designing the questionnaire and conducting the survey, this paper guarantees the reliability and rationality of the questionnaire data in terms of the following aspects:

1. The rationality of the item design for the questionnaire's measurement. Minglong Wu (2010) pointed out in he questionnaire statistical analysis practice-SPSS operation and application that the measurement items of the questionnaire should ensure the actual measurement of the 
Table 2. Questionnaire Descriptive Statistics

\begin{tabular}{|c|c|c|c|}
\hline Research attributes & Attribute & Effective sample size (No.) & Percentage $(\%)$ \\
\hline Sex & $\begin{array}{l}\text { male } \\
\text { female }\end{array}$ & $\begin{array}{l}102 \\
190\end{array}$ & $\begin{array}{l}34.93 \\
65.07\end{array}$ \\
\hline Age & $\begin{array}{l}\text { under } 25 \text { years } \\
25-35 \text { years old } \\
36-45 \text { years old } \\
\text { over } 46 \text { years }\end{array}$ & $\begin{array}{l}138 \\
84 \\
34 \\
36\end{array}$ & $\begin{array}{l}47.26 \\
28.77 \\
11.64 \\
12.33\end{array}$ \\
\hline Education & $\begin{array}{l}\text { High school and below } \\
\text { Junior College } \\
\text { Undergraduate } \\
\text { Master's degree or above }\end{array}$ & $\begin{array}{l}27 \\
33 \\
128 \\
104\end{array}$ & $\begin{array}{l}9.25 \\
11.30 \\
43.84 \\
35.62\end{array}$ \\
\hline Working condition & $\begin{array}{l}\text { Students } \\
\text { In-service Staff } \\
\text { Free entrepreneurs } \\
\text { Stay-at-home mother } \\
\text { Unemployed }\end{array}$ & $\begin{array}{l}116 \\
146 \\
13 \\
5 \\
12\end{array}$ & $\begin{array}{l}39.73 \\
50 \\
4.45 \\
1.71 \\
4.11\end{array}$ \\
\hline Purchase times & $\begin{array}{l}\text { once } \\
2-3 \text { times } \\
\text { 4-5times } \\
6-7 \text { times } \\
\text { More than } 8 \text { times }\end{array}$ & $\begin{array}{l}112 \\
75 \\
31 \\
14 \\
60\end{array}$ & $\begin{array}{l}38.36 \\
25.68 \\
10.62 \\
4.79 \\
20.55\end{array}$ \\
\hline Consumption amount & $\begin{array}{l}0-500 \mathrm{Rmb} \\
500-1000 \mathrm{Rmb} \\
1000-1500 \mathrm{Rmb} \\
1500-2000 \mathrm{Rmb} \\
\text { More than } 2000 \mathrm{Rmb}\end{array}$ & $\begin{array}{l}215 \\
47 \\
10 \\
7 \\
13\end{array}$ & $\begin{array}{l}73.63 \\
16.10 \\
3.42 \\
2.40 \\
4.45\end{array}$ \\
\hline
\end{tabular}

Figure 5. The Geographical Distribution of the Respondents

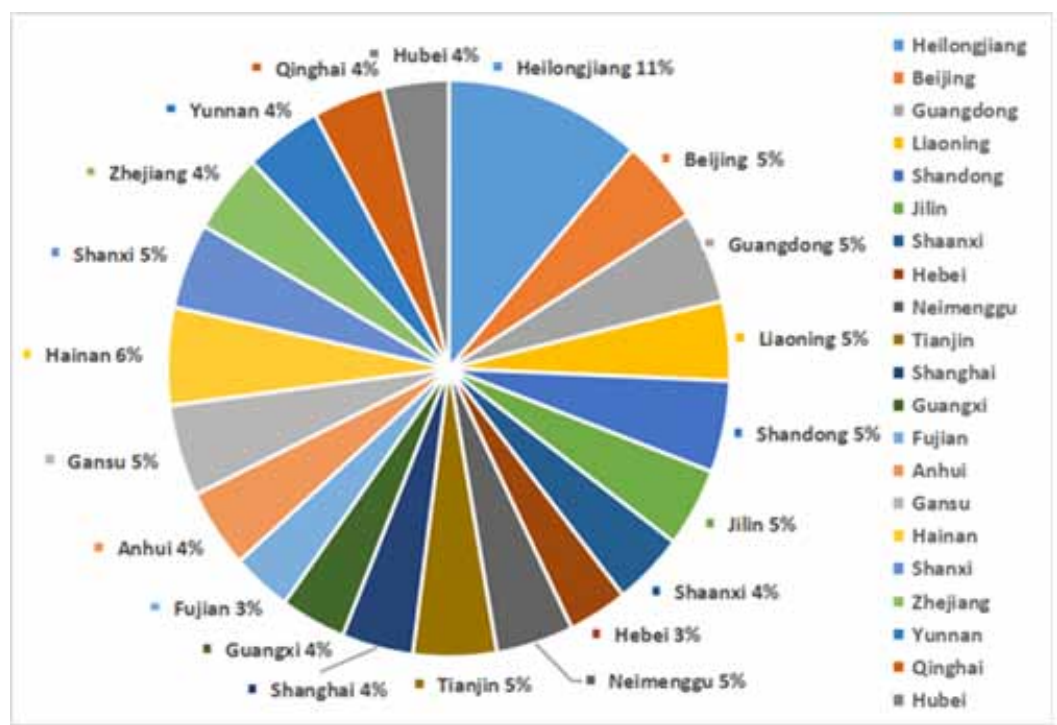


characteristics of each level. Therefore, the number of measurement items for each level of the questionnaire is more than or equal to three.

2. The sample quantity meets the requirements. Olusegun (2014) showed that the total number of samples needed when conducting empirical research should be more than 150 and reach fiveto-ten times the number of research variables. In order to ensure the reliability of the research, there are 15 items in this questionnaire, and the number of completed questionnaires recovered was 292, which meets the research requirements.

3. There is a relationship between the respondents and WeChat-based businesses. All respondents have had a WeChat-based shopping experience, and they are mainly from 21 provinces and cities such as Heilongjiang, Hainan, Beijing, Liaoning, Jilin, and so on. The geographical distribution is shown in Figure 5.

4. The anonymity of the questionnaire. In order to protect the privacy of the respondents, this questionnaire was filled out anonymously, which helped the respondents express their authentic ideas to ensure the objectivity of the questionnaire data.

5. The reliability of the questionnaire data. In order to ensure the reliability of the investigation's

Table 3. Reliability Analysis of Influencing Factors Scale of WeChat-based businesses Integrity

\begin{tabular}{|l|l|l|l|l|l|}
\hline \multicolumn{1}{|c|}{ Variables } & $\begin{array}{c}\text { Cronbach's a } \\
\text { Coefficient }\end{array}$ & Item & \multicolumn{1}{|c|}{ Variable } & $\begin{array}{c}\text { Cronbach's a } \\
\text { Coefficient }\end{array}$ & \multicolumn{1}{c|}{ Item } \\
\hline Payment security & 0.717 & 3 & After-sale Guarantee & 0.943 & 3 \\
Products and service quality & 0.872 & 3 & Word-of-mouth & 0.760 & 3 \\
WeChat-based business & 0.901 & 3 & Overall & 0.945 & 15 \\
Integrity & & & & \\
\hline
\end{tabular}

results, the reliability and validity of the scale data are analyzed. See the data analysis in 4.3 to ascertain the correctness of the empirical analysis.

\section{Data Analysis}

\section{Reliability Analysis}

Reliability analysis tests whether the indexes in the questionnaire are consistent, stable, and reliable. It generally reflects the good and low reliability of the test according to internal consistency (Zhang, 2007), and it is measured by calculating Cronbach's alpha coefficient. If the Cronbach's alpha coefficient is greater than 0.9 , the reliability of the scale should be high $(\mathrm{Li}, 2017)$. SPSS24.0 was used to test the scale. The results are shown in Table 3.

Table 4. Validity Analysis of Influencing Factors Scale of WeChat-based businesses Integrity

\begin{tabular}{|l|l|l|}
\hline \multicolumn{2}{|c|}{ KMO and Bartlett tests } \\
\hline \multirow{2}{*}{ KMO } & Approximate chi square & 0.973 \\
\hline \multirow{3}{*}{ KMO and Bartlett tests } & df & 3491.249 \\
\cline { 2 - 3 } & Sig. & 105 \\
\cline { 2 - 3 } & & 0.000 \\
\hline
\end{tabular}


The reliability analysis shows that Cronbach's alpha coefficient for the overall data is 0.945 , which is greater than 0.9 . Therefore, the scale of this survey has a high amount of consistency and reliability.

\section{Validity Analysis}

Validity analysis refers to the degree of how well the measured results reflect the proposed purpose. The higher the agreement between the measurement results and the content to be examined, the greater the validity and vice versa (Li, 2017). This paper calculated the KMO values and conducted Bartlett Spherical tests on the data by using SPSS24.0. If the actual value of the KMO is greater than 0.8 , the Bartlett spherical test chi-square approximation of each set of variables in the questionnaire is very large; if the significance probability is $<0.001$, then the validity test is satisfied. The validity analysis results for the factors affecting WeChat-based business integrity is shown in Table 4.

According to Table 4, the KMO value for the factors influencing how people view WeChat-based business integrity is $0.973>0.8$, indicating that the correlation difference among the factors in this survey is relatively small. The chi-square approximation of the Bartlett spherical test is 3491.249, which is very large, and the significant probability of the scale is less than 0.001 , which is highly significant.

From the results of the factor analysis and based on the principle of characteristic root $>=1$, the factors are rotated to obtain five factors (product and service quality, after-sale guarantees, payment security, word-of-mouth, and WeChat-based business integrity). The characteristic values of the scale are all greater than one and the cumulative contribution rate is $75.978 \%$. The reliability coefficient for each factor reaches 0.7 or more. Therefore, the scale of the factors the influence how people view WeChat-based business integrity has good validity.

\section{HYPOTHESIS VALIDATION}

From the reliability and validity test in the previous section, it is known that the reliability and validity of the micro-business integrity factor scale have reached the standard. In this section, Amos 23.0 was used in terms of structural equation modeling (SEM) to test the hypotheses of the factors affecting WeChat-based business integrity. Structural equation modeling (SEM) is a statistical mathematical analytic tool that is formed by multiple regression analysis and path analysis. It is widely used in psychology, economics, sociology, and so on. SEM is a kind of confirmatory analysis that aims to test the adaptability of the structural model through a path analysis according to the causal relationship among potential variables (Wu, 2009). In this paper, the data collected from the questionnaire are used to fit the structural equation model by inputting the data into Amos23.0 software. It can be seen from Figure 4 that this model includes four independent variables (product and service quality, after-sales guarantees, payment safety, and word of mouth) and one dependent variable (WeChat-

Table 5. Initial Fitting Index of Model

\begin{tabular}{|l|l|l|l|l|l|l|}
\hline \multicolumn{1}{|c|}{ Fitting Index } & \multicolumn{1}{c|}{ CMIN / DF } & \multicolumn{1}{c|}{ RMSEA } & \multicolumn{1}{c|}{ GFI } & \multicolumn{1}{c|}{ AGFI } & \multicolumn{1}{c|}{ NFI } & \multicolumn{1}{c|}{ CFI } \\
\hline Standard Value & $<3$ & $<0.08$ & $>0.9$ & $>0.8$ & $>0.9$ & $>0.9$ \\
\hline Actual Vale & 3.705 & 0.096 & 0.884 & 0.826 & 0.892 & 0.918 \\
\hline
\end{tabular}

based business integrity), and involve 15 measurement items in total. Based on the hypothesized relationship between the variables, a path map is drawn, and the data in SPSS24.0 is imported into the Amos23.0 software to calculate and verify the model. According to the results of the running model, we can judge whether or not the fit degree of the model meets the standard. The reference 
Table 6. Model Modified Fit Index

\begin{tabular}{|l|l|l|l|l|l|l|}
\hline \multicolumn{1}{|c|}{ Fitting Index } & CMIN / DF & \multicolumn{1}{c|}{ RMSEA } & \multicolumn{1}{c|}{ GFI } & \multicolumn{1}{c|}{ AGFI } & \multicolumn{1}{c|}{ NFI } & \multicolumn{1}{c|}{ CFI } \\
\hline Standard Value & $<3$ & $<0.08$ & $>0.9$ & $>0.8$ & $>0.9$ & $>0.9$ \\
\hline Actual Vale & 1.890 & 0.055 & 0.944 & 0.905 & 0.951 & 0.976 \\
\hline
\end{tabular}

standards are CMIN / DF < 3, GFI, NFI, TLI, CFI > 0.9, RMSEA $<0.08$, and then to judge whether or not the hypothesis of the relationship among the variables is true.

\section{Model Fitting Degree}

In this paper, Amos23.0 was used to analyze the model. The test results are shown in Table 5.

It can be seen in Table 5 that $\mathrm{AGFI}=0.826$ and $\mathrm{CFI}=0.918$, and both reached the standard value. However, CMIN/DF, RMSEA, GFI, NFI did not meet the standard requirements, indicating that the model was not completely consistent with the actual sample data and that the model should be further corrected. According to the fitting result for the model, the modification index (MI) value for some parameters were $>5$, which indicates that there is a need for the correction of the residual variables.

Combined with the indicators corresponding to the residual variables, this paper added paths to the individual modified indicator parameters of the model. The corrected model fitting results are shown in Table 6.

It can be seen in Table 6 that the fitting indexes of the model are within the standard value range, indicating that the model has a good fit and is acceptable.

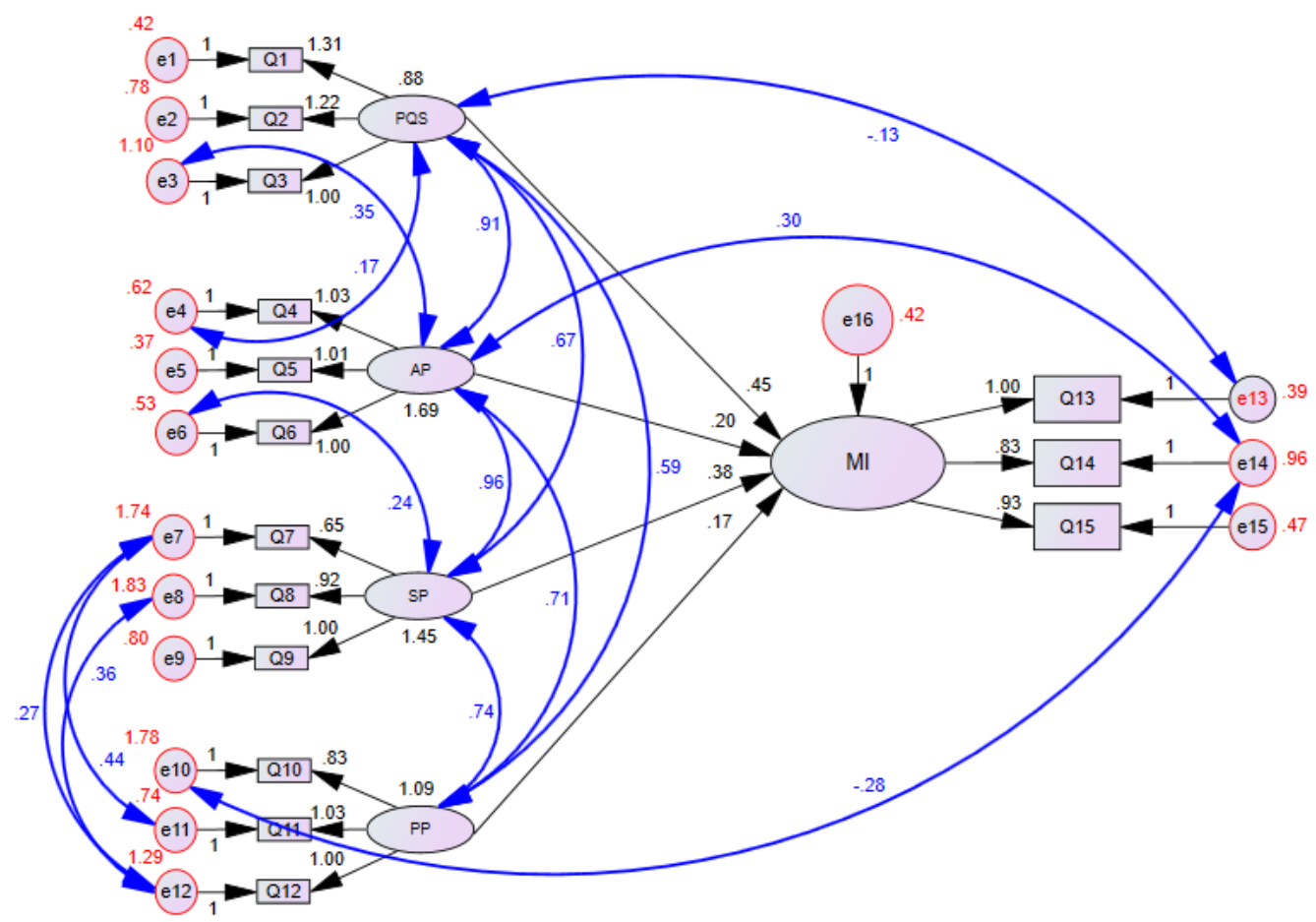


Table 7. Standardized Path Coefficient of the Model

\begin{tabular}{|l|l|l|l|l|l|l|}
\hline \multicolumn{2}{|c|}{ Path Coefficient } & Estimate & \multicolumn{1}{|c|}{ S.E. } & C.R. & \multicolumn{1}{c|}{ P } \\
\hline WeChat-based Business Integrity & $<--$ & Product and service quality & 0.449 & 0.128 & 3.516 & $* * *$ \\
\hline WeChat-based Business Integrity & $<---$ & Word-of-mouth & 0.174 & 0.081 & 2.132 & 0.033 \\
\hline WeChat-based Business Integrity & $<---$ & Payment security & 0.381 & 0.081 & 4.700 & $* * *$ \\
\hline WeChat-based Business Integrity & $<---$ & After-sale protection & 0.204 & 0.084 & 2.430 & 0.015 \\
\hline
\end{tabular}

Note: ${ }^{* * *}$ indicates the significance level $P<0.001,{ }^{* *}$ indicates the significance level $P<0.01,{ }^{*}$ indicates the significance level $P<0.05$

\subsection{Path Coefficient and Research Results}

The data is analyzed by Amos23.0 based on the maximum likelihood estimation method. The standardized path coefficients of the model are shown in Figure 6.

Note: PQS represents product and service quality; AP represents after-sale guarantees; SP represents payment security; PP represents word-of-mouth; WI represents WeChat-based business integrity

Figure 6 shows that the path coefficient of product and service quality, after-sale guarantees, payment security, and word-of-mouth to WeChat-based business integrity are all positive, which matches the assumptions. The standardized path coefficient of the model is shown in Table 7.

The above table shows that product and service quality, after-sale guarantees, payment security, and word-of-mouth have a significant and positive impact on the views of WeChat-based businesses integrity. The path coefficients of product and service quality and payment security are 0.449 and 0.381 , respectively, and the p-values reach a significance level of 0.001 . At the same time, the path coefficients of after-sale guarantees and word-of-mouth are 0.204 and 0.174 , respectively, and the $\mathrm{P}$-values are all at a significance level of 0.05 . Thus, hypothesis one (product and service quality has a significant and positive impact on the views of WeChat-based business integrity), hypothesis two (after-sale guarantees have a significant and positive impact on the views of WeChat-based business integrity), hypothesis three (payment security has a significant and positive impact on the views of WeChat-based business integrity), and hypothesis four (word-of-mouth has a significant and positive impact on the views of WeChat-based business integrity) are established.

At the same time, as can be seen in Table 7, the path coefficient results go from the largest to the smallest in the following order: product and service quality, payment security, after-sale guarantees, and word-of-mouth $(0.449>0.381>0.204>0.174)$. Therefore, the most important influence on the views of WeChat-based businesses is product and service quality, while having the least amount of influence is word-of-mouth.

In summary, in order to better establish an honest and trustworthy image for consumers, WeChatbased businesses should take the following measures:

1. Improve product and service quality. On the one hand, WeChat-based businesses should not sell "three no" products to consumers. On the other hand, WeChat-based businesses should carry out "three inspections" on their products, including performing a material inspection before processing, an inspection during processing, and performing a quality inspection of the finished products.

2. Ensure payment security. There are two main methods of payment for WeChat-based businesses: WeChat payments and Alipay payments. First, make full use of WeChat's or Alipay's official payment and compensation mechanisms to ensure the security of the consumer funds. Second, abide by the relevant laws and regulations, and bring WeChat payments into the scope of legal supervision. 
3. Improve after-sales support. First of all, WeChat-based businesses should provide consumers with their complete payment information, ensure the timely delivery of the goods received, and formulate after-sales service terms. Secondly, WeChat-based businesses should visit customers regularly and establish a customer base, so that customers can exchange goods at any time.

4. Establish a good reputation. The credibility of word-of-mouth communication is mainly reflected in the close relationships among friends, relatives, colleagues, classmates, and other groups. First, WeChat-based businesses should pay attention to the quality of their products, their market positioning, and their after-sales service when selling products, so as to lay a good foundation for word-of-mouth communication. Second, WeChat-based businesses should establish long-term, stable, and harmonious relationships with their customers.

With the development of the Internet and big data technology, along with the improvement of relevant laws and regulations, WeChat-based businesses have a more rational and rigorous choice of product quality and marketing models. In the background of mass entrepreneurship and a sharing economy and with the improvement of the WeChat-based business environment, WeChat-based businesses should develop toward greater standardization and better branding.

\section{CONCLUSION}

The structural equation model was used to analyze the factors influencing the views of WeChatbased business integrity. It can be concluded that product and service quality, after-sale guarantees, payment security, and word-of-mouth have significant and positive impact on the views of WeChatbased business integrity. The most significant factor affecting the views of WeChat-based business integrity is product and service quality, followed by payment security, then after-sales guarantees, and the least significant factor is word-of-mouth. This shows that consumers often consider product and service quality to be their primary concern while shopping in the WeChat friendship circle. This is because product and service quality is the most direct reflection of WeChat-based business integrity. Consumer doubts about the word-of-mouth of WeChat-based businesspeople indicates that people realize that word-of-mouth is rather subjective and cannot really reveal the actual level of WeChat-based business integrity. Thus, word of mouth has less of an impact on WeChat-based business integrity when compared with other factors. With the development of Internet technology and the improvement of laws and regulations, WeChat-based businesses have a more rational and rigorous choice of product quality and marketing behavior. 
In the era of the sharing economy, online shopping will become the mainstream choice for customer consumption. As such, business integrity has become an important intangible asset in retaining customers, and the research about the factors influencing the views of business integrity has become increasingly important. On the basis of this study, researchers can carry out the following research. First, new factors can be considered in the design of the questionnaire. Second, the interviewees can be further adjusted and expanded, from choosing WeChat users in China to choosing WeChat users in other countries, so as to compare the different requirements of WeChat users in different countries regarding WeChat-based business integrity. Third, this method can be used more widely to study the factors influencing the views of business integrity in other e-commerce businesses.

\section{ACKNOWLEDGMENT}

This work is funded by Humanities and Social Science Planning Fund Project of Ministry of Education (15YJA630074).

\section{REFERENCES}

Amdt, J. (1967). Word-of-mouth advertising: A review of the literature. Advertising Research, (5), 98-110.

Chang, X. J., Ma, Z. G., Lin, M., Yang, L., \& Hauptmann, A. G. (2017). Feature interaction augmented sparse learning for fast kinetic motion detection. IEEE Transactions on Image Processing, 26(8), 3911-3920. doi:10.1109/TIP.2017.2708506 PMID:28574355

Chang, X. J., Ma, Z. G., Yang, L., Zeng, Z. Q., \& Hauptmann, A. G. (2017). Bi-level semantic representation analysis for multimedia event detection. IEEE Transactions on Cybernetics, 47(5), 1180-1197. doi:10.1109/ TCYB.2016.2539546 PMID:28113831

Chang, X. J., \& Yang, Y. (2017). Semi-supervised feature analysis by mining correlations among multiple tasks. IEEE Transactions on Neural Networks and Learning Systems, 28(10), 2294-2305. doi:10.1109/ TNNLS.2016.2582746 PMID:27411230

Chang, X. J., Yu, Y. L., Yang, Y., \& Xing, E. P. (2017). Semantic pooling for complex event analysis in untrimmed videos. IEEE Transactions on Pattern Analysis and Machine Intelligence, 39(8), 1617-1632. doi:10.1109/ TPAMI.2016.2608901 PMID:28113653

China Internet Association WeChat Business Working Group. (2017). Research Report on China's WeChat Business Industry in 2016. Author.

China Internet Association WeChat Business Working Group. (2018). Development Report on China's WeChat Business Industry in 2017. Author.

Christina, F., \& Seock, Y. K. (2019). Chinese consumers' perceptions toward social media platform for shopping and eWOM intention: A study of WeChat. International Journal of Fashion Design, Technology and Education, 2(12), 199-207.

Chu, S. C., Lien, C. H., \& Cao, Y. (2018). Electronic word-of-mouth (eWOM) on WeChat: Examining the influence of sense of belonging, need for self-enhancement, and consumer engagement on Chinese travelers' eWOM. International Journal of Advertising, 1(38), 26-49.

Fang, J. W. (2019). Analysis of the status quo of the micro-commerce market under the background of big data network and suggestions for improvement. Modern Marketing, (04), 68-69.

Fu, H.N. (2018). Talking about the development of China's micro-business based on STWO analysis. Times Finance, (30).

Fu, Q. Q. (2019). Problems in the protection of consumer rights under the micro-business model and their solutions. Journal of Harbin University, (07), 65-68.

Hu, X. L. (2016). Investigation and development trend of WeChat business. Economic Forum, (1), 133-137. 
Hui, G. L. (2019). SWOT analysis of micro-business development based on trust mechanism under mobile internet. Value Engineering, 38(20), 115-117.

Jiao, Q., \& Liu, S. H. (2015). Research on the influencing factors of trust in shopping circle of WeChat. China Business \& Trade, (09), 55-57.

Lan, Y. F. (2018). The development trend of micro-commerce and the analysis of college students' micro-business. Journal of Jiamusi Vocational Institute, (11), 420-421.

Li, C., Zhang, Z. Y., \& Zhang, L. F. (2018). A novel authorization scheme for multimedia social networks under cloud storage method by using MA-CP-ABE. International Journal of Cloud Applications and Computing, 8(3), 32-47. doi:10.4018/IJCAC.2018070103

Li, G., Niu, W. J., Tan, J. L., Batten, L., \& Chang, L. (2017). Curbing collusive cyber-gossips for business brand management. Enterprise Information Systems, 10(11), 1457-1461. doi:10.1080/17517575.2017.1309687

L, H. Z. (2017). Methodology of Management Research (3rd edition). Xi' an Jiaotong University Press. Li, P., Gao, W., Chen, H. J., Luo, C., Zhang, Y., \& Yang, L. J. (2017). C2C WeChat business integrity feedback system design. Modern Business, (18): 37-38.

Li, P., Gao, W., Chen, H. J., Luo, C., Zhang, Y., \& Yang, L. J. (2017). Credit problems and countermeasures in the development of C2C WeChat business. Modern Business, (12):42-43.

Li, S. H., \& Yang, L. (2015). Research on the influencing factors of consumers' purchase decision in C2C We Chat shopping. Consumer Economics, 31(05):55-59+50.

Li, Z. H., Nie F. P., \& Chang, X. J. (2017). Beyond trace ratio: Weighted harmonic mean of trace ratios for multiclass discriminant analysis. IEEE Transactions on Knowledge and Data Engineering, 29(10): 2100-2110.

Liao, W. F., \& Chen, F. (2016). Analysis of the current situation and development trend of WeChat businesses in China. Contemporary Economics, (07):46-48.

Maestre-Gongora, G. P., \& Bernal, W. N. (2019). Conceptual Model of Information Technology Management for Smart Cities: SmarTICity. Journal of Global Information Management, 27(2), 159-175. doi:10.4018/ JGIM.2019040109

Morrar, R., Abdeljawad, I. J., Kisa, A., \& Younis, M. Z. (2019). The role of information and communications technology (ICT) in enhancing service sector productivity in Palestine: An international perspective. Journal of Global Information Management, 27(1), 47-65. doi:10.4018/JGIM.2019010103

Osmal, S., \& Kang, K., \& Iwona, M. (2019). Uncertainty Avoidance and Consumer Cognitive Innovativeness in E-Commerce. Journal of Global Information Management, (2), 59-77.

Magnus, S. (1998). Customer satisfaction and its consequences on customer behavior revisited. International Journal of Service Industry Management, 9(2).

Olusegun, A. H., Ashari, H., \& Nordin, N. (2014). Influence of top management commitment, stakeholder pressure and public concern on sustainable environmental manufacturing practices in Malaysia data screening and preliminary analysis. International Journal of Business and Management, 2(11), 189-196.

Qian, F. Y., Li, J., \& Liu, X. (2016). On the construction of trust mechanism of WeChat business. Modern Business, (09), 50-51.

Sangeeta, G., \& Narsimha, G. (2018). Secure NoSQL for the social networking and e-commerce based bigdata applications deployed in cloud. International Journal of Cloud Applications and Computing, 8(2), 113-129. doi:10.4018/IJCAC.2018040106

Shan, G. J. (2018). Analysis of the development of micro-business based on WeChat friends circle. China Journal of Commerce, (31), 162-163.

Shen, Y. Y. (2019). Research on the development status and future trend of rural micro-business. Market Modernization, (11), 8-9.

Shi, B. F. (2017). An analysis of the status quo of the business of micro-business in vocational schools-Based on the investigation of Japanese vocational colleges. E-Business Journal, (1), 91-92. 
Wang, J. S. (2014). Challenges and countermeasures of WeChat business regulation in the era of big data. China Industrial and Commercial New, 13(3).

Wang, M. X. (2017). The development status, problems and suggestions for sustainable development of WeChat businesses in China. China Circulation Economy, (15), 7-8.

Wang, W. M. (2019). Research on the status quo of micro-business management and marketing strategy. The Farmers Consultant, (05), 230-231.

Wang, Z. R., \& Qi, X. H. (2017). Investigation and analysis of the status quo of micro-business entrepreneur management. Theoretic Observation, (12), 102-103.

Wu, M. L. (2009). Structural equation model. Chongqing University Publisher.

Wu, M. L. (2010). Questionnaire statistical analysis practice. Chongqing University Publisher.

Yang, S., Chen, S. M., \& Li, B. (2016). The role of business and friendships on WeChat Business: An emerging business model in China. Journal of Global Marketing, 29(4), 174-187. doi:10.1080/08911762.2016.1184363

Zhang, H., \& Tian, M. F. (2007). Application of reliability analysis in questionnaire design. Statistics \& Decisions, (21), 25-27.

Zhang, W. M., \& Wen, X. (2018). Analysis on the status quo and countermeasures of China's micro-business development. Marketing Management Review, (12), 102-103.

Zhang, Y. L. (2018). SWTO analysis of WeChat Business development. Modern Economic Information, (24), 334.

Yanling Xiao (1963-), professor, doctoral supervisor, She has been awarded University of Shanghai for Science and Technology Ph.D. in management science and engineering (2006), Haerbin Engineering University M.E. in Management Engineering (1993), Northeast Petroleum University B.S. in Oil recovery engineering (1986). She is the discipline leader of Daqing management association, responsible for and involved in nearly 30 national, provincial or bureau level scientific research projects, compiled 3 textbooks, and published more than 50 academic papers as the first author. She mainly engaged in system evaluation, enterprise reputation, environmental responsibility and other fields.

Bingjun Tong (1993-) was an undergraduate recommended graduate student, and is studying for a master's degree in the School of Economics and Management of Northeast Petroleum University. She mainly engaged in corporate reputation and management engineering.

Mingxin Cui (1978-), Master of Management, Associate Professor, She is currently studying for a doctor's degree, member of Daqing Management Society, teacher of Northeast Petroleum University, has been engaged in the research of corporate ethics and social responsibility and resource and environmental economics.

Yanmei Sheng (1977-), associate professor, currently she is studying for a doctor's degree, and received a Bachelor's degree in Northeast Petroleum University in 2000 and a master's degree in Harbin University of Commerce in 2007. Her major is accounting from undergraduate to graduate. She won a teaching quality prize of our university in 2006. The courses that she teaches include principles of accounting, financial management, and accounting theory and methods. In recent years, her research direction is social responsibility and supply chain management. 